\title{
Improved load frequency characteristics with genetically tuned supercapacitor energy storage in interconnected power system
}

\section{S. Zahid Nabi Dar* and Mairaj-ud-din Mufti}

\author{
Department of Electrical Engineering, \\ NIT Srinagar, India \\ Email: Zahidnabi21@gmail.com \\ Email: muftimd@yahoo.com \\ *Corresponding author
}

\begin{abstract}
In this article the integration of genetically tuned supercapacitor energy storage system (SCESS) with a three-area power system is focused. The part of governor deadband along with generation rate limit in the event of a pragmatic power system is considered. Every region is joined with a SCES unit. A S-function based predictive control model is additionally fused to it and the voltage loop of SCESS is utilised as feedback. Simulation studies carried in MATLAB SIMULINK environment reflect critically enriched reaction in load-frequency and tie-line power oscillations. The SCESS voltage and power reaction are additionally portrayed.
\end{abstract}

Keywords: supercapacitor energy storage system; SCESS; load frequency control; LFC; area control error; ACE; new area control error; NACE; genetic algorithm; GA; adaptive generalised predictive control; AGPC.

Reference to this paper should be made as follows: Dar, S.Z.N. and Mufti, M-u-d. (2018) 'Improved load frequency characteristics with genetically tuned supercapacitor energy storage in interconnected power system', Int. J. Industrial Electronics and Drives, Vol. 4, No. 1, pp.16-24.

Biographical notes: S. Zahid Nabi Dar received his BTech in Electrical Engineering and MTech in Power System Engineering and is pursuing his PhD program at the Department of Electrical Engineering, NIT Srinagar.

Mairaj-ud-din Mufti received his BE in Electrical Engineering from the Regional Engineering College, Srinagar, India, in 1986. He received his MTech and PhD in 1991 and 1998, respectively, from the Indian Institute of Technology (IIT), New Delhi.

\section{Introduction}

With developments in innovation new measurements are summing up to ever intricate and as of now extending power system yet the future lies in the productive control of energy. The researchers are focused with the use of various energy storage systems, for instance, redox flow battery and battery energy storage systems in load frequency control (LFC) applications as discussed in Li and Joos (2008) and Ribera et al. (2001). A large portion of these systems have low time span of usability with respect to the charge/discharge cycles. Some of these devices mean ecological worries by spillage of unsafe gasses amid their operation. There has been a trend in the recent past to incorporate various flexible AC transmission systems (FACTS) devices as discussed in Soliman et al. (2010). Various control strategies including evolutionary methods are incorporated to control the dynamics and power constraints as discussed in Soliman et al. (2009). Further utilising of modern power electronics especially in renewable energy systems has picked up as suggested in Bayoumi (2015). In this work utilisation of SCES unit is proposed in case of a three area power system. The SCESS has huge edge over rest of the energy storage devices that are unmatched by contemporary energy storage devices. Supercapacitors have no rotating parts, thus neither heating nor any cooling is required. Additionally inside SCESS there is no inward chemical response. The other favourable circumstances of SCESS are that toward the end of their life they are easy to dispose, being lead free, with no memory effect and can be effectively bundled. The pre-eminent energy storage devices ought to have high energy density and demands the system to be ready in a flash to be charged/discharged. High energy batteries discharge gradually, while energy densities of high power capacitors are low. The supercapacitors have high energy densities like the batteries and high rate of charging/discharging. Likewise the upkeep rates and supplanting rates with the supercapacitors are least in contrast with other energy storage devices available in the market. Battery energy storage for LFC of an interconnected power system was attempted as reflected in Aditya and Das (2001), Wood and Wollenberg (1996) and Francoise et al. (2005). But batteries 
however, have low power density, high maintenance requirements and a limited life cycle. They get quickly aged due to frequent charging and discharging. Therefore, batteries are not suitable for the continual LFC duty, as these get immediately matured due to incessant charging and discharging. Also the maintenance rates and replacement schedules with the supercapacitors are minimum in comparison to other energy storage devices present in the market.

Most of the researches have ignored the essential nonlinearities like the governor deadband and generation rate constraints (GRC) which lead to persistent oscillations in the system. The inclusion of such factors into the system will give us the clear understanding of a practical three area power system. SCES device is incorporated within the system by taking into account the effects of governor deadband as well as the GRC as discussed in Elgerd and Fosha (1970), Concordia et al. (1957) and Tripathy et al. (1982). As there is innate nonlinearity present in the power system, so procedures in view of estimated linear models won't work as the working point changes around the system. Conversely, predictive control offers adaptable mapping of irregular nonlinearities which make it appropriate for controlling SCES device inside power system. So by considering previously mentioned criteria, an adaptive generalised predictive control (AGPC) of the SCESS is proposed. This plan basically bargains of two noteworthy components in particular the optimiser that represents optimal control response in future and the system model that should be controlled. In this scheme receding horizon principle has been utilised. Essentially at every inspecting period each control factor forecast is inferred through an interim of Ny tests, and the optimum control issue is settled. In this work, part of AGPC strategy has been used and connected to a three area power system with incorporation of GRC and governor deadband. It has been found that there is a critical diminishment of the tie-power deviations and the frequency variations with incorporation of SCES device. Further the constrained SCESS power is additionally delineated through extensive Simulations carried out in the MATLAB SIMULINK environment by consolidating a three area power system.

\section{Mathematical representation of the model utilised in simulation studies}

Literature shows the governor turbine system is extremely slow in regard to the excitation system, which is exceptionally quick. At the point when there is a sudden drop in load demand the SCES in a split second gets charged to its maximum magnitude, in this way retaining some part of the extra energy in the system and when the network restores back to its steady state, the extra energy is discharged by SCES to the system and the stored energy again achieves its nominal value

Generally, the governor turbine framework is languid in regard to the excitation system, which is robust. Hence, changes in terminal voltage can be redressed by the excitation system and changes in system frequency are addressed by governor-turbine framework, thus one can decouple the governor-turbine control loop with automatic voltage controller (AVR) loop as discussed in Kwanty et al. (1997) and Tripathy et al. (1982). Essentially it can be said when the governor turbine under the assumption of having kept up a set estimation of terminal voltage, as the load frequency model manages real power/frequency behaviour, the excitation system model will not be required in the investigation. In this work a three area interconnected power system is used with indistinguishable regions interlinked via a tie line as shown in Figure 1.

Figure 1 Three area power system with SCES

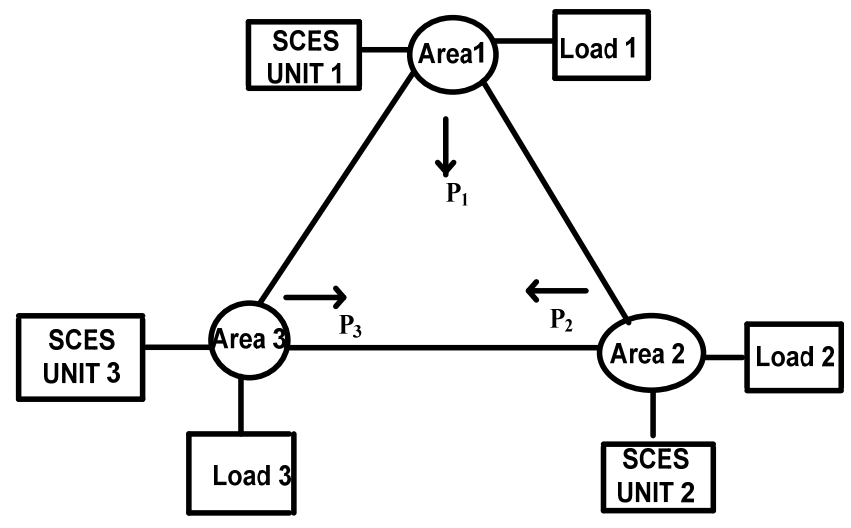

Each control area comprises generators worked by means of non-reheat setup based steam turbines. Because of incorporation of deadband and GRC, keeping in mind the end goal to give realististic look to power system it was seen that these components brought about infusing low-frequency oscillation inside the system. However, there is more pervasiveness of high frequency swings to prevail. The vast periodic oscillations have no power interchange between power zones since system is oscillating together as examined in Hiyama (1982). In simulation studies it was seen that smaller deadbands bring about energising motions for tie-line natural frequency wherein the bigger deadbands produce longer-periodic motions. Further it is unrealistic for every governor in the system to have comparable incremental regulation deadband in addition to similar speed of reaction. Likewise, at a discretionary time moment, the system would lie at any area inside the deadband. It can be seen, the development of deadband widths bring about arbitrary changes of the numerous governors from their mean positions. Additionally, contrasting units of the system will be removed by comparing their respective deadbands in a successive way which brings about minute effective deadbands of their corresponding deadbands consecutively. It was found that the scopes of the oscillations reflect towards the deadband and not towards the normal of all deadbands considered for various generators connected to the system, (Taylor et al., 1979) utilised numerous discrete deadbands working in parallel and each dead-band had separate width inside the normalised governor turbine model. 


\section{SCES control module}

In this work, investigations were done on a three area power system. To symbolise the dynamic conduct of a supercapacitor a few models are recommended in the literature as discussed in Iqbal et al. (2009), Francoise et al. (2005), Johnson et al. (2001) and Ter-Gazarian, (2011). The primary model configuration is constructed with a distributed capacitance and resistance just like the case of transmission-line model. The secondary design consists of multi-branch RC network with dissimilar time constraints for the respective branches as shown in Figure 2.

Figure 2 Two-branch RC equivalent circuit of a supercapacitor

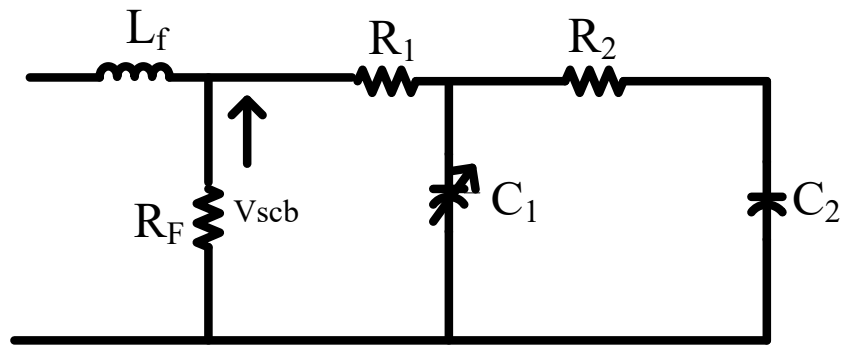

A two branch RC equivalent circuit is shown in Figure 2. The branch $\mathrm{R}_{1} \mathrm{C}_{1}$ is the principal branch which governs the instant operation of the supercapacitor in a very limited time range. It is ascribed as a fast branch. The secondary branch designated as $\mathrm{R}_{2} \mathrm{C}_{2}$ is a very slow branch and reflects the system behaviour in time spanning around a few minutes, with $R_{f}$ we represent the equivalent leakage resistance. It has an effective role to play in extended energy storage applications as discussed in Muyeen et al. (2007) and Moreno et al. (2006). The quick responding branch is dependent on capacitor voltage and is generally designed with a constant part $\mathrm{C}_{\mathrm{O}}$ and a linearly changing voltage-governed component $\mathrm{C}_{\mathrm{V}}$.

$$
\mathrm{C}_{1}=\mathrm{C}_{0}+\mathrm{C}_{\mathrm{V}}=\mathrm{C}_{0}+\mathrm{K}_{\mathrm{V}} \mathrm{V}_{1}
$$

In majority of short-term operations, needing the supercapacitor to supply power for some seconds, the sluggish branch can be ignored. Generally for standard operations the capacitor voltage dependency is also disregarded and the supercapacitor is designed solely as resistance in series with a lumped capacitance as described in Kinjo et al. (2006) and Zubieta and Bonert (2000).

Figure 3 Configuration of the SCES and its PCS in a control area

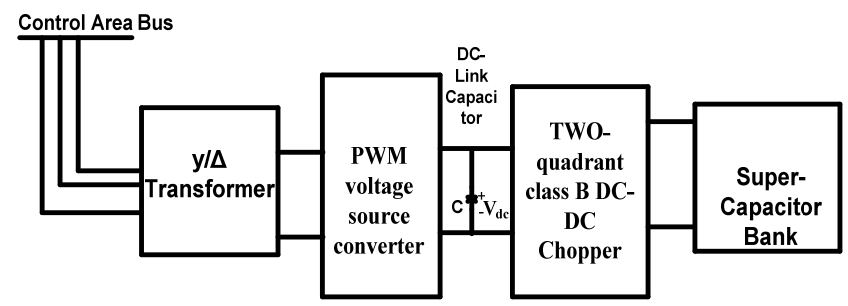

Figure 3 depicts the arrangement of SCES system inside a control area. The power conditioning system (PCS) comprises pulse-width modulated (PWM), voltage source converter (VSC), interlinked by a dc-dc bidirectional buck-boost convertor via a dc-link capacitor. The converter utilises IGBT power devices for switching purposes. With appropriate gating signals administered to the $\mathrm{V}_{\mathrm{sc}}$, the $\mathrm{dc}$ link voltage $V_{d c}$ is kept constant all through. For a uniform dc-link voltage, the transfer of power through the SCESS can be represented by a combination of buck-boost convertor and the capacitor. The supercapacitor is depicted by a combination of an equivalent series resistance and a lumped capacitance. The dual switches namely $\mathrm{S}_{1}$ and $\mathrm{S}_{2}$ inside the buck-boost converter are switched in a specific manner such that while one of them operates, the other remains switched off. Hence, in case the duty ratio of switch $\mathrm{S}_{1}$ happens to be $\mathrm{D}_{1}$ then automatically the duty ratio of the switch $\mathrm{S}_{2}$ would be (1-D).

Figure 4 (a) Bidirectional buck-boost converter connected to supercapacitor (b) Equivalent circuit $\mathrm{x}=\mathrm{g}_{1}$ for instantaneous model and $\mathrm{x}=\mathrm{D}_{1}$ for average model

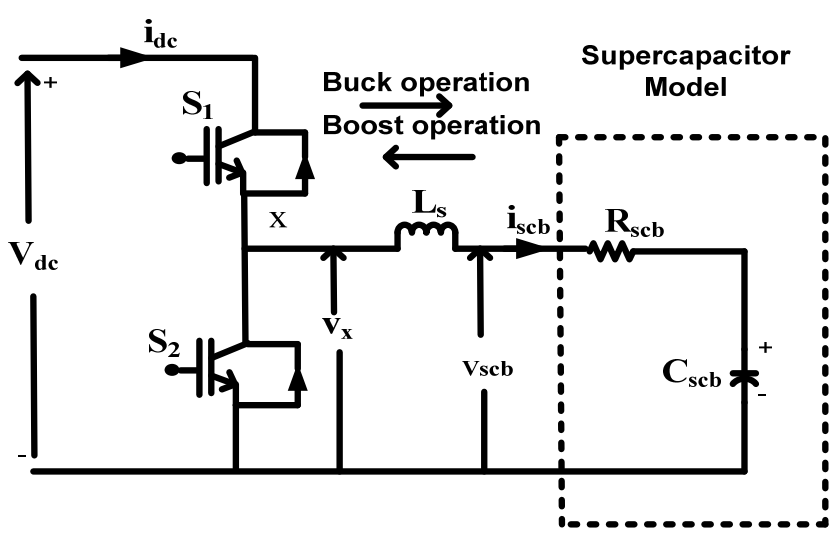

(a)

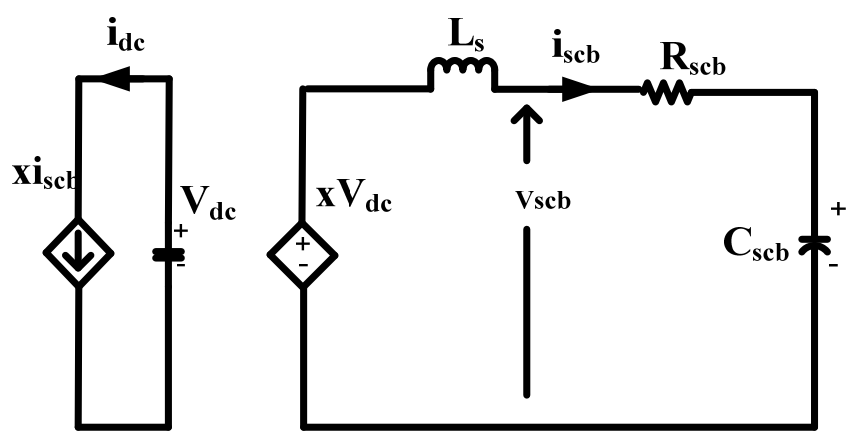

(b)

The instant and average value for voltage at position $\mathrm{x}$ are thus given by:

$$
\begin{aligned}
& \mathrm{V}_{\mathrm{x}}=\mathrm{g}_{1} \mathrm{~V}_{\mathrm{dc}} \\
& \mathrm{V}_{\mathrm{scb}}=\mathrm{D}_{1} \mathrm{~V}_{\mathrm{dc}}
\end{aligned}
$$

where $g_{1}$ is the gate controlled logic connected to switch $S_{1}$ as shown in Figure 4. Depending upon the size of $V_{x}$ in reference to the normal supercapacitor voltage, $V_{\text {scb}}$, the buck-boost converter could work in two modes. In case $\mathrm{V}_{\mathrm{x}}>\mathrm{V}_{\mathrm{scb}}$, the converter capacities in buck mode in the forward direction and the power in this mode gets exchanged from dc-link to supercapacitor. If $\mathrm{V}_{\mathrm{x}}<\mathrm{V}_{\mathrm{scb}}$, the 
converter capacities in boost mode in the turnaround course, all things taken into consideration power would be exchanged from supercapacitor to dc link. The essential control of the SCESS is, governed by suitable power command $\mathrm{P}_{\text {scb. }}$. This is achieved by applying a reasonable control pulse to boost converter switches.

\section{Control of SCESS power}

Here the primary work is engaged towards incorporation of a SCESS unit with the power system to give LFC support. The principle point with this plan is to limit deviations brought in frequency and tie line power brought by load disturbances. While going for accomplishing these objectives, there are different imperatives as discussed in Ribera et al. (2001) and Shupbach and Balda (2004) on the control of SCESS, These are as follows:

1 The supercapacitor voltage ought to come back to its nominal rating at steady state.

2 The supercapacitor ought to be worked inside the reasonable voltage range.

3 The power demand ought not to surpass the converter ratings.

4 The operation of the SCES system ought not to meddle with tie-line bias control scheme of LFC.

5 Undesirable generation manoeuvring ought to be kept minimum.

Figure 5 Reference tracking scheme

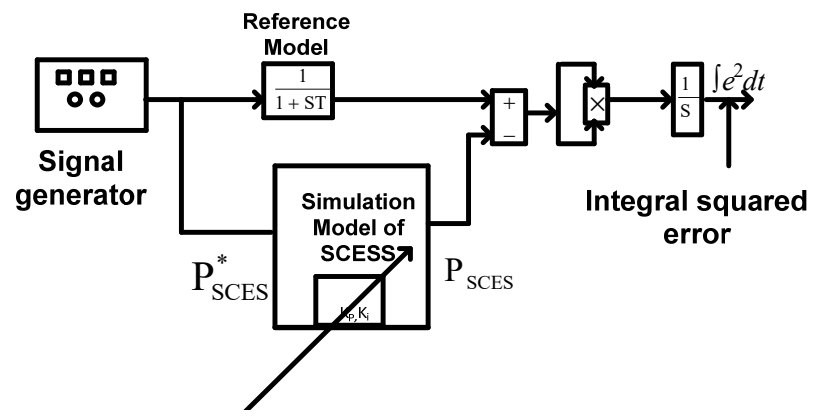

In this work state - variable model based GPC formulation is used which is regarded as the better choice than a transfer function model. Therefore, the real time identified model needs to be converted to a state variable representation. Normally in GPC formulation an incremental state space model is used. This is because several control situations require a non-zero steady state control signal which is achieved by penalising $\Delta \mathrm{u}(\mathrm{k})$ in the GPC cost function. The incremental model approach for SCES control will however, defeats the purpose. The non-zero offset has to be avoided to allow the SCES and governor controls to play their desirable role. Therefore, incremental state variable representation is avoided in this work and a normal variable representation is developed. The SCESS was fed by a frequency generator having amplitude of 0.01 and frequency of 1 hertz. The reference power command was sustained and the real power was followed through setting the PI controller by utilising genetic tuning algorithm as described in Cao and Wu (1999), proportional and integral gain was obtained as 0.9978 and 2.1778 respectively. From Figure 5, it can be plainly observed that the reference and real power are superbly overlapping.

\section{Generalised predictive control}

generalised predictive control (GPC) is a successful system which has watched much attention of the researchers in the recent past. At the outset the predictive control algorithms were applied around 30 years back with the end goal of controlling multidimensional mechanical processes with constraints. With arrival of computers, we are currently in a position to use predictive control innovation with complex system. The principle point of incorporation of quick reacting energy storage device for example, SCES inside a power system for improved LFC is to regulate system frequency and tie-line control. The viable use of a compact rated SCES device accompanies a disadvantage of forcing constraints that must be handled with a control methodology. The SCES system and its converter administer its power ratings by producing a desired power command for the SCES system. The secondary control loop enforces the SCES system to follow the power command received from the supervisory controller, by producing proper gating signals for the SCES converter switches. In the earlier works carried over, the SCES device limits were enforced over the control signal in an adhoc-manner, without incorporation of the constraints in the controller formulation. The GPC fuses two fundamental components of the system required to be controlled and the modelling of the optimiser that represents the control responses for the controller in future. At each sampling moment, forecasts of the controlled and additionally constrained factors are continued over a period of $\mathrm{N}_{\mathrm{Y}}$ samples and the optimal control problem is explained. For the most part we accept the control signal to remain uniform past $\mathrm{N}_{U}$ samples. $\mathrm{N}_{\mathrm{Y}}$ and $\mathrm{N}_{\mathrm{U}}$ are delineated as the prediction horizon and the control horizon. On accomplishing the outcome for the optimum control problem the essential component produced by the optimum sequence is executed and $\beta$ the substitute components are rejected/relinquished. For control related problems in case of power systems, normally a third-order model is sufficient. Errors resulting on account of small model orders are reduced through online identification of the model at each sampling instant. Essentially the parameters of the low-order model do not have a particular physical significance. The cause effect connection between control variable $U$ and controlled variable $Y$ for each control region can be explained by the following form:

$$
\mathrm{Y}(\mathrm{m})=\sum_{\mathrm{i}=1}^{\mathrm{N}} \alpha_{\mathrm{i}}(\mathrm{y})(\mathrm{m}-\mathrm{i})+\sum_{\mathrm{i}=1}^{\mathrm{N}} \beta_{\mathrm{i}}(\mathrm{y})(\mathrm{m}-\mathrm{i})
$$

This equation depicts that present output can be anticipated by making utilisation of $\mathrm{n}$ sets of the past output and 
information estimations. Here number $\mathrm{N}$ presents the order in case of autoregressive exogenous model (ARX). Recursive least squares (RLS) identification algorithm is utilised to evaluate the model parameters. In this work state variable model based GPC plan has been utilised. An observable canonical form state variable model has the following form as given in Gopal (2008):

$$
\mathrm{X}(\mathrm{m}+1)=\mathrm{Ax}(\mathrm{m})+\mathrm{bu}(\mathrm{m})
$$

Presently the optimal control problem for a GPC can be expressed as

$$
\begin{aligned}
\min J & =\sum_{\mathrm{i}=1}^{\mathrm{N}}\left[\mathrm{y}^{\wedge}(\mathrm{m}+\mathrm{i})-\mathrm{w}(\mathrm{m}+\mathrm{i})\right]^{2} \mathrm{Q} \\
& +\sum_{\mathrm{i}=1}^{\mathrm{N}}[\mathrm{u}(\mathrm{m}+\mathrm{i}-1)]^{2} \mathrm{R}
\end{aligned}
$$

subject to the constraint being satisfied, $\mathrm{w}$ is the desired value vector of system output, Q\&R are weight matrices. Substituting equation (5) in equation (6) the optimisation problem is reduced to a general quadratic form, i.e.

$$
\begin{aligned}
& \min J(u)=U^{T} H U+2 G^{T} u \\
& \text { s.t. } A_{q p} U \leq b c
\end{aligned}
$$

where $\mathrm{G}=-\left[\mathrm{W}-\mathrm{SX}(\mathrm{m})^{\mathrm{T}}\right][\mathrm{Q}][\mathrm{S}]$ and $\mathrm{H}=[\mathrm{L}]^{\mathrm{T}}[\mathrm{Q}][\mathrm{L}]+\mathrm{R}$.

Thereafter the least squares algorithm for estimation of parameters is given by subsequent equations:

$$
\begin{aligned}
\theta(\mathrm{m}) & =\left[\mathrm{a}_{1}(\mathrm{~m}) \mathrm{a}_{2}(\mathrm{~m}) \ldots . \mathrm{a}_{\mathrm{N}}(\mathrm{m}) \mathrm{b}_{1}(\mathrm{~m}) \mathrm{b}_{2}(\mathrm{~m}) \ldots . \mathrm{b}_{\mathrm{N}}(\mathrm{m})\right]^{\mathrm{T}} \\
\psi(\mathrm{m}) & =[\mathrm{y}(\mathrm{m}-1) \ldots \mathrm{y}(\mathrm{m}-\mathrm{n}) \mathrm{u}(\mathrm{m}-1) \ldots \mathrm{u}(\mathrm{m}-\mathrm{n})]^{\mathrm{T}} \\
\hat{\theta}(\mathrm{m}) & =\hat{\theta}(\mathrm{m}-1)+\mathrm{K}(\mathrm{m})\left[\mathrm{y}(\mathrm{m})-\hat{\theta}(\mathrm{m}-1) \varphi^{\mathrm{T}}\right] \\
\mathrm{M}(\mathrm{m}) & =\frac{\mathrm{P}(\mathrm{m}-1) \psi) \psi(}{\lambda+\varphi^{\mathrm{T}}(\mathrm{m}) \mathrm{P}(\mathrm{m}-1) \varphi(\mathrm{m})} \\
\mathrm{P}(\mathrm{m}) & =\left[\mathrm{I}-\mathrm{M}(\mathrm{m}) \Psi^{\mathrm{T}}(\mathrm{m})\right] \mathrm{P}(\mathrm{m}-1) / \lambda
\end{aligned}
$$

In the above mentioned equations an approximation of $\theta(\mathrm{m})$, wherein the caret represents the anticipated qualities $0<\lambda<1$ is the forgetting factor, I is the identity matrix, $\mathrm{M}(\mathrm{m})$ is the adjustment gain vector and $\mathrm{P}(\mathrm{m})$ is the covariance matrix. The excellence of this scheme is that with combining of load disturbance influence impacts of the system are recognised online. Subsequently along these lines of plan the future disturbance model is exhibited inside the distinguished model, thus this procedure brings about avoidance of disturbance independently. Standard RLS $(\lambda=1)$ as given in Zak (2003) is not in a position to anticipate the parameters for procedures having time invariance. This component could lead to disastrous results in adaptive control, where there is time invariance in the process because of use of wrong estimations of anticipated parameters in plan approach. The use of RLS may prompt specific issues like progressive speed of parameter estimation and sometimes identification goes to rest; in this manner as a correlative measure it is fitting to expand the richness of control signal by expansion of pseudo random binary sequence/white noise. One more important consideration is that the $\mathrm{i} / \mathrm{p}$ signal ought to have adequate bandwidth so all procedural methods of intrigue are all well energised. It is seen in control applications identified with power system a white noise of bandwidth capacity going up to $10 \mathrm{~Hz}$ happens to work reasonably. In our SCES control issue, control variable $\mathrm{Y}$ is proposed to be an element of area control error (ACE) and voltage deviation from the ostensible estimation of SCES. Since the different deviations in particular tie-power frequency and SECS voltage should accomplish zero magnitude in steady state, the parameters $\alpha, \beta$ specified in the above equation are unknown. Besides their magnitude changes with varying operating conditions of the system.

\section{Constraints imposed by SCES}

The converter rating directs (chooses) the most extreme power restrain taken care by SCES while charging/releasing conditions. By considering SCES power command as the control variable, the converter rating enforces following limitations on control vector $\mathrm{u}$ :

$$
\mathrm{fu} \leq \mathrm{f}
$$

where $\mathrm{f}=\left(\begin{array}{l}\mathrm{I} \\ -\mathrm{I}\end{array}\right)$ and $\mathrm{u}=\left(\begin{array}{l}\overrightarrow{\mathrm{u}}_{\max } \\ \overrightarrow{\mathrm{u}}_{\min }\end{array}\right) \overrightarrow{\mathrm{u}}_{\min }$ and $\overrightarrow{\mathrm{u}}_{\max }$ are vectors.

Since the converter rating of SCES is $1 \%$ of area-capacity. In this way $\mathrm{U}_{\max }=0.01 \mathrm{pu}$ and $\mathrm{U}_{\min }=-0.01$ $\mathrm{pu}$, in the full form equation is:

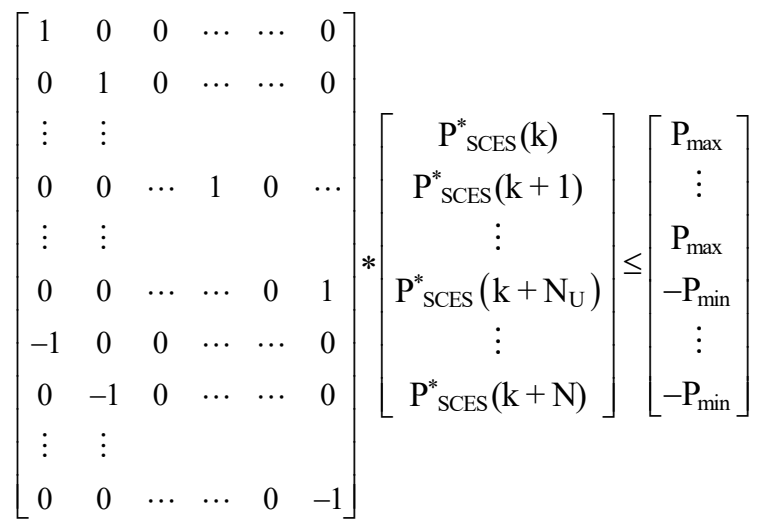

Figure 6 GAPC scheme

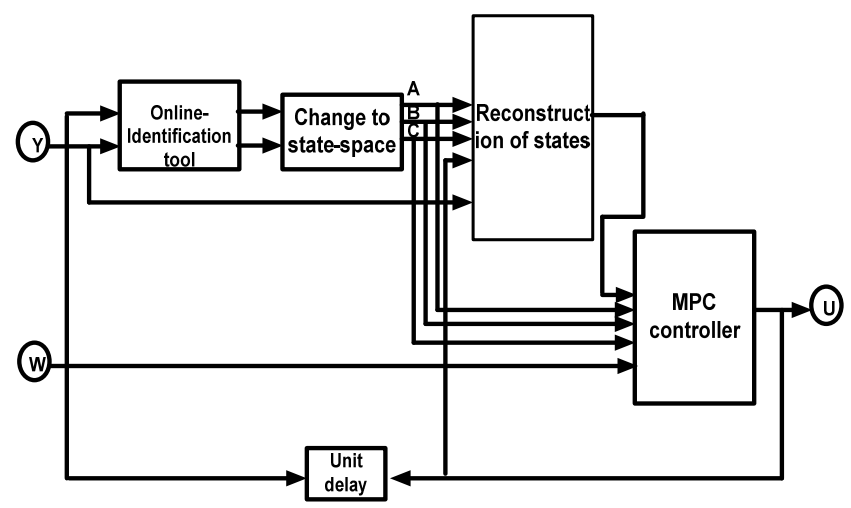


Figure 7 Reference power tracking (see online version for colours)

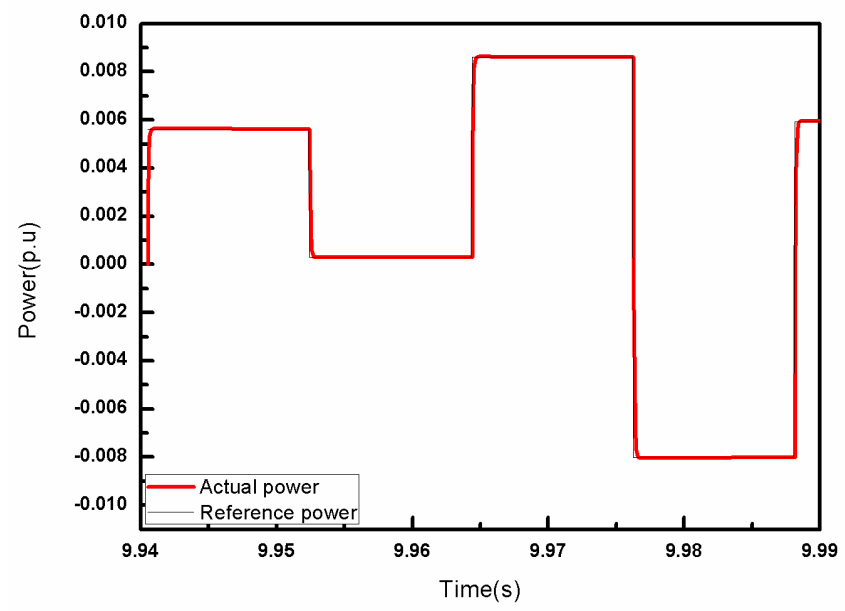

Figure 8 Plots of frequency variations for load perturbation profile of Appendix A in case of three area power system (see online version for colours)
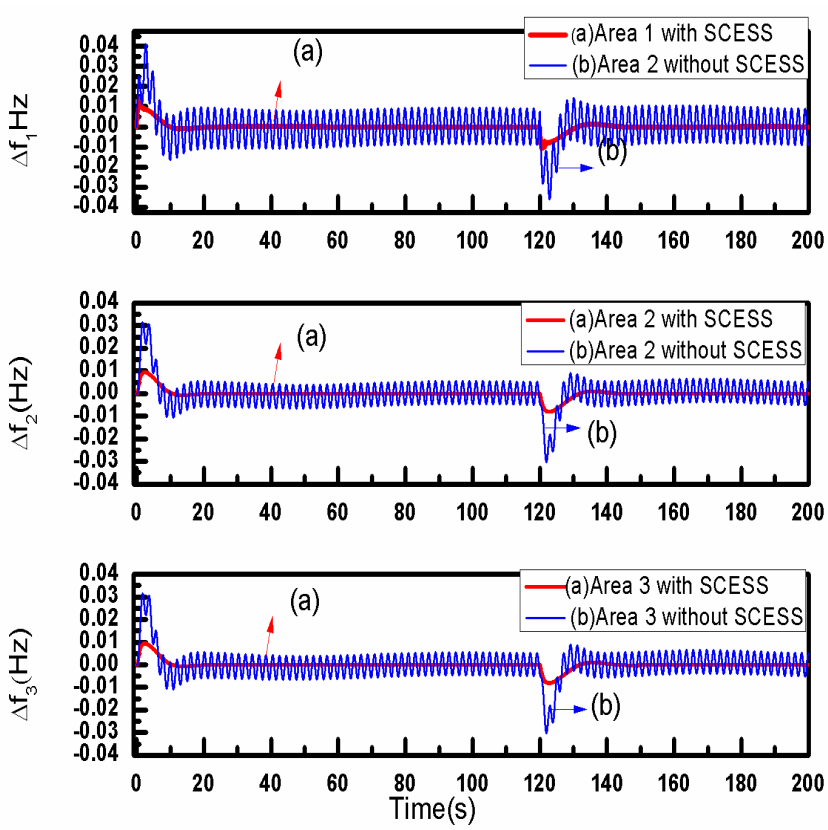

The operational block diagram delineating the implementation aspects of the proposed plan is depicted in Figure 6. The block depicted as the SCES represents the control model. It is exceptionally essential to check that the variable $\mathrm{P}_{\mathrm{SCES}}$ gives the power fed to the SCES by the individual control area respectively. It has been considered the controlled variable $y$ is a function of two factors namely the derivative of ACE and the deviations in the SCES voltage. It is represented by a single term new area control error (NACE). The exact term used for controlled variable is:

$$
\begin{aligned}
\mathrm{y}(\mathrm{m})= & \mathrm{ACE}(\mathrm{m})+\mathrm{m}_{1} \Delta \mathrm{V}_{\mathrm{SCES}}(\mathrm{m})+\mathrm{m}_{2}\left(1-\mathrm{z}^{-1}\right) \operatorname{ACE}(\mathrm{m}) \\
& +\mathrm{m}_{3}\left(1-\mathrm{z}^{-1}\right) \Delta \mathrm{V}_{\mathrm{SCES}}(\mathrm{m})
\end{aligned}
$$

where $\mathrm{m}_{1}, \mathrm{~m}_{2}$ and $\mathrm{m}_{3}$ are constraints and the ending two terms in the above mentioned equation are derivative terms, which lead to damping. As $\mathrm{y}$ is a combo of deviation factors, hence subsequently we keep the reference as zero.

Besides such plans are optimised for a confined range of load disturbances. In this work, another control technique is proposed for upgraded and productive operation of a SCES system for LFC support. This plan is directed by the GPC and is equipped for managing all the control issues related with the operation of SCES in a methodical way. Primarily long range prediction (LRP) has been used to test whether any of the variables like SCES voltage is in range or not and accordingly modify the SCES voltage. For executing of GPC, an appropriate prediction model of the system is designed. Essentially there is inalienable nonlinearity unpredictability and high order exhibited by a practical power system. In this way it is not plausible to design a GPC scheme for the SCES system in the light of a point by point, settled - parameter model of the system. Rather, a settled system, low-order direct model is used wherein its parameters are distinguished online. The subsequent GPC in this way is versatile. The present work uses a state-variable based GPC detailing which is viewed as a superior approach than transfer function model. In this way, the continuous distinguished model should be changed over to a state-variable model portrayal. GPC is typically created for a controlled auto-regressive integrated moving average model (CARIMA) in which an incremental state-space model is utilised as a part of GPC detailing. This is on the grounds that many control situations require a non-zero steady state control signal which is accomplished by penalising $(\mathrm{m})$ in the GPC schemes as depicted by Chalupa (2009). The incremental model approach for SCES system will however vanquish the purpose. A non-zero offset has to be avoided to allow the SCES system and governor control to play their desirable role. For this reason incremental state variable representation is avoided in this article and instead a normal state variable representation developed.

Figure 9 Plots of tie-power variations for load perturbation profile of Appendix A in case of three area power system (see online version for colours)
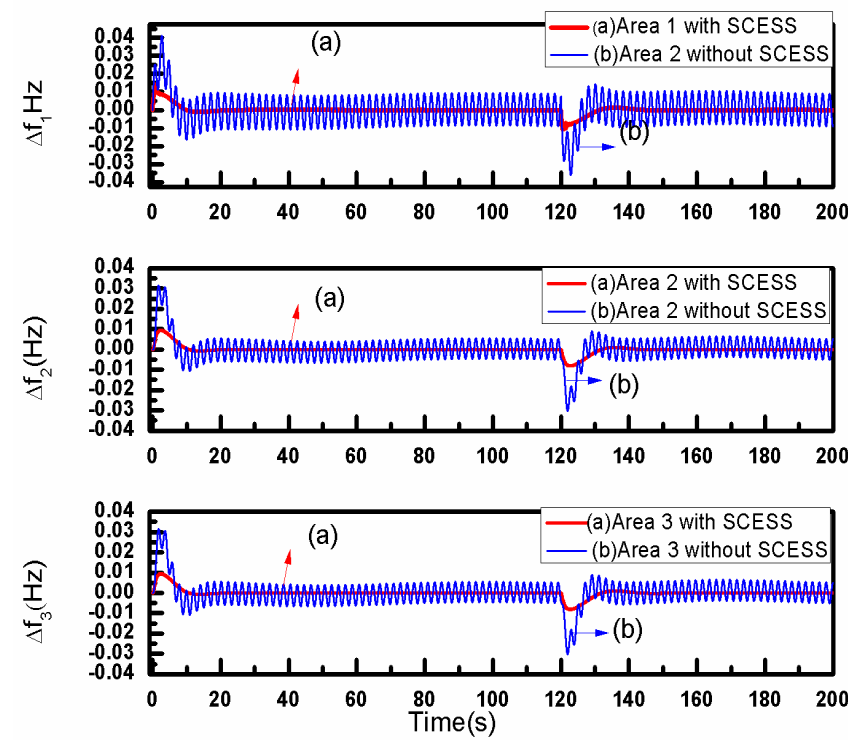
Figure 10 Plots of SCES voltage variations for load perturbation profile of Appendix A in case of three area power system (see online version for colours)
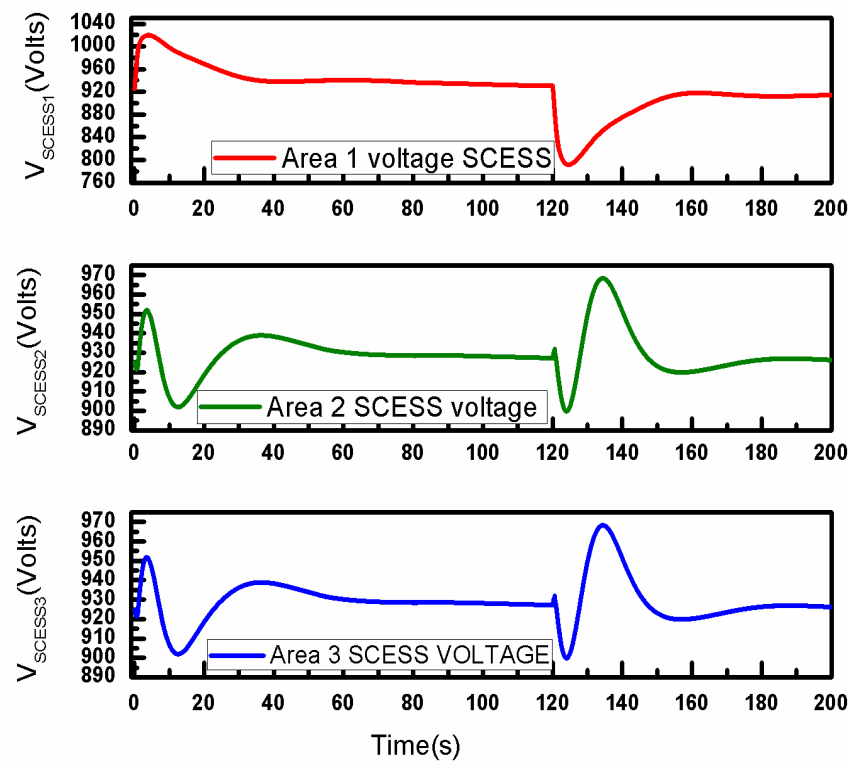

Figure 11 Plots of SCES power variations for load perturbation profile of Appendix A in case of three area power system (see online version for colours)
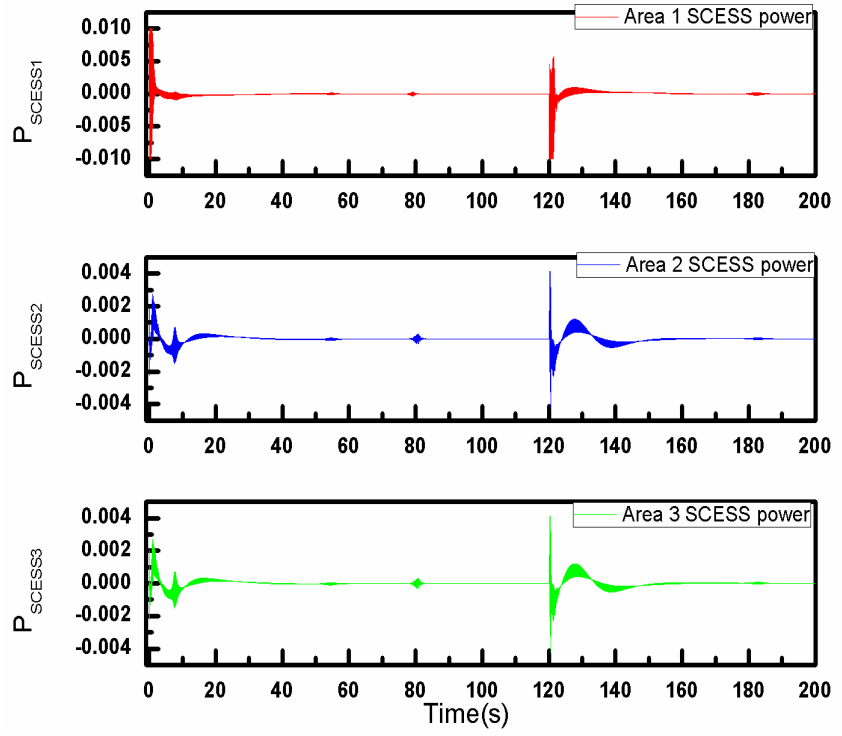

Due to the presence of various tie-lines, if there should arise an occurrence of multi-area power system control, the reaction of such framework turns out to be considerably more oscillatory. The three area power system is subjected to a load disturbance ,magnitude of power system governing factors and rating of supercapacitor as detailed in Appendices ' $A$ ' ' $B$ ' and ' $C$ ' respectively. It can be seen from the simulation results of the plots depicted for the instance of three area power system, that the recommended plan is exceptionally effective in handling the load aggravations. It is unmistakably observed that the SCES voltages get re-established to ostensible rating after dealing with the disturbance. These simulation results can be briefly described as follows:
1 With comparison of the control scheme for SCES in regard with different methods particularly the proportional control we get significantly speedier damping of electromechanical oscillations.

2 The proposed scheme makes the SCES device to recover back towards its nominal energy or voltage, in the wake of confronting perturbation, considerably quicker as contrasted with other schemes. In such cases proportional control based plans are ineffectual.

3 The plots visibly exhibit an admirable execution of proposed scheme, wherein a control region by means of a GAPC controller alongside SCES demonstrates exceptional response in the wake of handling a disturbance.

Figure 12 Constrained power plot (see online version for colours)

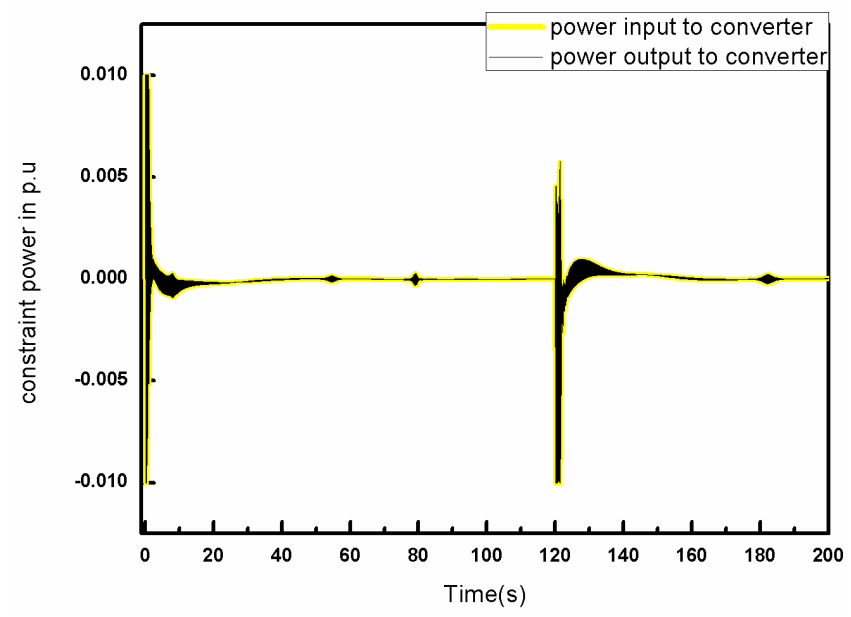

7 Conclusions

An adaptive predictive technology has been proposed. In Matlab Simulink Environment a special block has been generated for GAPC and control plot by utilising the S-function coding inside MATLAB. Therefore, an extremely dynamic utilisation of Simulink implementation is recommended. The recommended control approach uses the reference power command straightforwardly for a changing term named as NACE. The resultant control signals meet intense control objective. This control plan is exceptional in contrast with the effectively utilised plans already existing in the literature.

\section{References}

Aditya, S.K. and Das, D.(2001) 'Battery energy storage for load frequency control of an interconnected power system', Electric Power Systems Research, Vol. 58, No. 3, pp.179-185.

Bayoumi, H.E.E. (2015) 'power electronics in renewable energy smart grid: a review', International Journal of Industrial Electronics and Drives, Vol. 2, No. 1, pp.43-61. 
Cao, Y.J. and Wu, J.Q.H.G. (1999) 'Teaching genetic algorithm using MATLAB', International Journal of Electrical Engineering Education, Vol. 36, No. 2, pp.139-153.

Chalupa, P. (2009) 'Predictive control using self tuning model predictive controllers library', in Proceedings of the 17th Conference on Process Control Slovakia, pp.419-425.

Concordia, C., Kirchmeyer, L.K. and Szymanski, E.A. (1957) 'Effect of speed governor deadband on tie line power and frequency control performance', Transaction of the AIEE on Power Apparatus and Systems, Vol. 76, No. 3, pp.429-434.

Elgerd, O.I. and Fosha Jr, C.E. (1970) 'Optimum megawatt-frequency control of multi-area electric energy systems', IEEE Transactions on Power Apparatus and Systems, Vol. PAS-89, No. 4, pp.556-563.

Francoise, J.N.M., Gaulous, H., Outbib, R. and Berthon, A.(2005) ' $42 \mathrm{~V}$ power net with supercapacitor and battery for automotive applications', Journal of Power Sources, Vol. 143, No. 1, pp.275-283.

Gopal, M. (2008) Digital Control and State Variable Methods, Tata McGraw Hill, India.

Hiyama, T. (1982) 'Optimization of discrete-type load-frequency regulators considering generation-rate constraints', Proceedings of the IEEE, Vol. 129, No. 6, pp.285-289.

Iqbal, S.J., Mufti, M.D., Lone, S.A. and Mushtaq, I. (2009) 'Supercapacitor based energy storage device for improved load frequency control', Electric Power System Research, Vol. 79, No. 1, pp.226-233.

Johnson, D., Malengret, M. and Pillay, P. (2001) 'Electromechanical storage for rural electrification', Journal of Energy in Southern Africa, Vol. 12, No. 1, pp.322-328.

Kinjo, T., Senjyu, T., Uezato, K. and Fujita, H. (2006) 'Output leveling of wind power generation system by EDLC energy storage system', Electrical Engineering in Japan, Vol. 154, No. 4, pp.34-41.

Kwanty, H.G., Kalnitsky, K.C. and Bhatt, A. (1997) 'An optimal tracking approach to load-frequency control', IEEE Transactions on Power Apparatus and Systems, Vol. 12, No. 2, pp.187-192.

Li, W. and Joos, G. (2008) 'A power electronic interface for a battery supercapacitor hybrid energy storage for wind power applications', IEEJ Power Electronic Specialist Conference, PESC, pp.1762-1768.

Moreno, J., Ortuzar, M.E. and Dixon, J.W. (2006) 'Energy management system for a hybrid electrical vehicle, using ultraca, pacitors and neural networks', IEEE Transactions on Industrial Electronics, Vol. 53, No. 2, pp.614-623.

Muyeen, S.M., Shishido, S., Ali, M.H., Takahashi, R., Murata, T. and Tamura, J. (2007) 'Application of energy capacitor system to wind power generation', Electrical Wind Energy, Vol. 11, No. 4, pp.332-35, 'Load frequency control using Bat inspired algorithm based dual mode gain scheduling of PI controller for interconnected power systems', International Journal of Electrical Power and Energy Systems, Vol. 64, pp.365-374.

Ribera, P.F., Johnson, B.K., Crow, M.L., Arsoy, A. and Liu, Y. (2001) 'Energy storage for advanced power applications', Proceedings of the IEEE, Vol. 89, No. 12, pp.1744-1756.
Soliman, H.M., Bayoumi, H.E. and Hassan, M.F. (2009) 'Power system stabilizer design for minimal overshoot and control constraint using swarm optimization', Electric Power Components and Systems, January, Vol. 37, No. 1, pp.111-126.

Soliman, H.M., Bayoumi, H.E. and Awadallah, M.A. (2010) 'Design of reconfigurable fault-tolerant PSS and FACTS controllers', Electric Power Components and Systems, Vol. 37, No. 1, pp.111-126.

Shupbach, P.M. and Balda, J.C. (2004) ' 35 Kw ultracapacitor unit for power management of hybrid electric vehicles: bidirectional DC-DC converter design', IEEE 35th Annual Power Electronic Specialists Conference, PESC 04, Vol. 3, pp.2157-2162.

Taylor, C.W., Lee, T.Y. and Dave, D.P. (1979) 'Automatic generation control analysis with governor deadband effects', IEEE Transactions on Power Apparatus and Systems, Vol. PAS-98, No. 6, pp.2030-2036.

Ter-Gazarian, A.G. (2011) Energy Storage for Power Systems, IET Power and Energy Series, UK.

Tripathy, S.C., Hope, G.S. and Malik, O.P. (1982) 'Optimization of load-frequency control parameters for power systems with reheat steam turbines and governor deadband nonlinearity,' IEEE Proceedings of the IEEE, Vol. 129, No. 1, pp.10-16.

Wood, A.J. and Wollenberg, B.F. (1996) Power Generation, Operation and Control, John Wiley and Sons, New York.

Zak, S.H. (2003) System and Control, Oxford, New York.

Zubieta, L. and Bonert, R.(2000) 'Characterization of double-layer capacitors for power electronics applications', IEEE Transactions on Industry Applications, Vol. 36, No. 1, pp.199-205.

\section{Appendix A}

Load disturbance profile for three areas

$$
\begin{aligned}
& \Delta \mathrm{PD} 1=0.01 \text { p.u. } \\
& \Delta \mathrm{PD} 2=0.00 \text { p.u. } 0<\mathrm{t} \leq 120 \mathrm{~s} \\
& 0.01 \text { p.u } \mathrm{t}>120 \text { s } \\
& \Delta \mathrm{PD} 3=0.00 \text { p.u. } \mathrm{t} \leq 200 \mathrm{~s} \\
& 0.01 \text { p.u } \mathrm{t}>120 \text { s }
\end{aligned}
$$

\section{Appendix B}

System data

$$
\begin{aligned}
& \mathrm{K}_{\mathrm{P} 1}=\mathrm{K}_{\mathrm{P} 2}=\mathrm{K}_{\mathrm{P} 3}=120 \mathrm{~Hz} /(\text { p.u. } \mathrm{MW}) \\
& \mathrm{T}_{\mathrm{P} 1}=\mathrm{T}_{\mathrm{P} 2}=\mathrm{T}_{\mathrm{P} 3}=20 \mathrm{~S} \\
& \mathrm{~T}_{\mathrm{T} 1}=\mathrm{T}_{\mathrm{T} 2}=\mathrm{T}_{\mathrm{T} 3}=0.3 \\
& \mathrm{~T}_{\mathrm{G} 1}=\mathrm{T}_{\mathrm{G} 2}=\mathrm{T}_{\mathrm{G} 3}=0.2 \\
& \mathrm{R}_{1}=\mathrm{R}_{2}=\mathrm{R}_{3}=2.4 \mathrm{~Hz} /(\text { p.u. MW }) \\
& \mathrm{B}_{1}=\mathrm{B}_{2}=\mathrm{B}_{3}=0.425 \text { p.uMW/radian } \\
& \mathrm{T}_{\text {power-three area }}=0.08674 \text { P.U.MW/Hz }
\end{aligned}
$$




\section{Appendix C}

SCES and predictive controller data

Maxwell Boostcap Supercapacitor (BM0D0018-P390) (Three in series)

$$
\begin{aligned}
& \mathrm{C}_{\text {scb }}=6 \mathrm{~F} \\
& \mathrm{~V}_{\mathrm{SCES}}^{0}=925 \mathrm{~V}\left(\mathrm{~V}_{\mathrm{SCES}}=585-1170 \mathrm{~V}\right)
\end{aligned}
$$

\section{Converter:}

$$
\mathrm{V}_{\mathrm{dc}}=2.5 \mathrm{KV}, \mathrm{P}=750 \mathrm{~kW}(0.01 \mathrm{pu})
$$

Model $\quad \mathrm{L}_{\mathrm{S}}=5 \mathrm{Mh}$,

PCS rating $=0.01$ p.u.

$\mathrm{N}_{\mathrm{Y}}=20$.

$\mathrm{N}_{\mathrm{U}}=10$.

$\mathrm{T}_{\mathrm{S}}=0.1 \mathrm{~s}$. 